\title{
Anexo \\ Instituciones judeo-progresistas ICUF (1941-1970)
}

Nota: Los nombres de las entidades y las fechas fundacionales en algunos casos remiten a agrupaciones de principios de siglo $\mathrm{XX}$, y en otros a formaciones y sedes de los años 40 y 50, lo cual no significa que no existiesen asociaciones previas en varias de las localidades.

\begin{tabular}{|c|c|c|}
\hline Instituciones & le fundación & Localidad \\
\hline \multicolumn{3}{|c|}{ ARGENTINA } \\
\hline $\begin{array}{l}\text { Asociación Cultural Israelita } \\
\text { Residentes de Varsovia }\end{array}$ & 1945 & $\begin{array}{l}\text { Villa Crespo, Ciudad de Buenos } \\
\text { Aires (CABA) }\end{array}$ \\
\hline $\begin{array}{l}\text { Asociación Cultural Israelita de Córdoba } \\
(\mathrm{ACIC}) \text { y Escuela Sholem Aleijem }\end{array}$ & 1913 & Córdoba \\
\hline $\begin{array}{l}\text { Asociación Cultural Israelita de } \\
\text { Tucumán (ACIT) }\end{array}$ & 1952 & San Miguel de Tucumán \\
\hline $\begin{array}{l}\text { Asociación Cultural y Deportiva y } \\
\text { Escuela Jaim Zhitlovsky-CEAEZ (Centro } \\
\text { de Ex Alumnos de Escuela Zhitlovsky) }\end{array}$ & 1940 & Villa del Parque y Paternal, CABA \\
\hline Asociación Israelita Pro-Arte IFT (I-Dramst) & 1932 & Once-Balvanera, CABA \\
\hline $\begin{array}{l}\text { Asociación Israelita y Centro Educativo } \\
\text { Recreativo (CER) Sarmiento }\end{array}$ & 1951 & Villa Crespo, CABA \\
\hline $\begin{array}{l}\text { Ateneo Juventud Israelita Biblioteca } \\
\text { Obrera I.L.Peretz y Centro Cultural } \\
\text { Israelita de Rosario (CCIR) }\end{array}$ & 1940 & Rosario \\
\hline $\begin{array}{l}\text { Centro Cultural y Deportivo I.L.Peretz } \\
\text { de Villa Lynch }\end{array}$ & 1940 & $\begin{array}{l}\text { Villa Lynch, San Martín, } \\
\text { provincia de Buenos Aires }\end{array}$ \\
\hline Centro Cultural David Berguelson & 1949 & Villa Urquiza-Parque Chas, CABA \\
\hline $\begin{array}{l}\text { Centro Cultural Israelita de Mendoza } \\
\text { Escuela I.L.Peretz y Centro Cultural } \\
\text { Ana Frank }\end{array}$ & 1951 & Mendoza \\
\hline
\end{tabular}

(Archivos, año VIII, $\mathrm{n}^{\circ}$ 15, septiembre de 2019, pp. 71-73) 


\begin{tabular}{|c|c|c|}
\hline $\begin{array}{l}\text { Centro Cultural Israelita Emanuel } \\
\text { Ringuelblum }\end{array}$ & 1953 & Pompeya, CABA \\
\hline Centro Cultural Israelita I.L.Peretz de Lanús & s 1940 & Lanús, provincia de Buenos Aires \\
\hline $\begin{array}{l}\text { Centro Cultural Israelita (CIR) } \\
\text { Manuel Belgrano de Ramos Mejía }\end{array}$ & 1932 & $\begin{array}{l}\text { Ramos Mejía, } \\
\text { provincia de Buenos Aires }\end{array}$ \\
\hline Centro Cultural Peretz Hirschbein & 1952 & Villa Luro, CABA \\
\hline $\begin{array}{l}\text { Centro Cultural I.L.Peretz de } \\
\text { San Fernando }\end{array}$ & 1940 & $\begin{array}{l}\text { San Fernando, } \\
\text { provincia de Buenos Aires }\end{array}$ \\
\hline $\begin{array}{l}\text { Centro Literario y Biblioteca Israelita } \\
\text { Max Nordau y Escuela Popular Israelita } \\
\text { Sarmiento }\end{array}$ & 1912 & $\begin{array}{l}\text { La Plata, } \\
\text { provincia de Buenos Aires }\end{array}$ \\
\hline $\begin{array}{l}\text { Club Israelita Zalman Raizen y Escuela } \\
\text { Sarmiento de Avellaneda }\end{array}$ & ca. 1920 & $\begin{array}{l}\text { Avellaneda, } \\
\text { provincia de Buenos Aires. }\end{array}$ \\
\hline Colonia vacacional Zumerland & 1950 & $\begin{array}{l}\text { Mercedes, provincia de Buenos } \\
\text { Aires. Experiencias en: Córdoba } \\
\text { (1959-1979), Mendoza y Tucumán } \\
(1957-1960)\end{array}$ \\
\hline Escuela Israelita Januz Korchak & 1949 & La Paternal, CABA \\
\hline Hogar Cultural Méndele & 1925 & $\begin{array}{l}\text { Gral. San Martín (centro), } \\
\text { provincia de Buenos Aires }\end{array}$ \\
\hline $\begin{array}{l}\text { Asociación Cultural y Deportiva } \\
\text { Scholem Aleijem }\end{array}$ & 1930 & La Paternal, CABA \\
\hline $\begin{array}{l}\text { Sociedad Cultural Israelita Isaac } \\
\text { León Peretz de Santa Fe }\end{array}$ & 1912 & Santa Fe \\
\hline
\end{tabular}

URUGUAY

\begin{tabular}{lcc}
\hline $\begin{array}{l}\text { Centro Cultural Morris Winchevsky } \\
\text { (CCMW) }\end{array}$ & 1925 & Barrio Centro. Montevideo \\
$\begin{array}{l}\text { Asociación Cultural Israelita Jaim } \\
\text { Zhitlovsky (ACIZ) }\end{array}$ & 1950 & \\
\hline Club Obrero "Avangard" y Escuela & 1929 & Barrio Goes. Montevideo \\
\hline
\end{tabular}

BRASIL

\begin{tabular}{lcl}
\hline $\begin{array}{l}\text { Instituto Israelita Brasileiro de } \\
\text { Cultura e Educação y Colegio } \\
\text { Israelita-Brasileiro Scholem Aleichem }\end{array}$ & 1928 & Tijuca, Río de Janeiro \\
\hline $\begin{array}{l}\text { Associação Femenina Israelita } \\
\text { Brasileira (AFIB) y }\end{array}$ & 1947 & Río de Janeiro \\
Colonia de férias Kinderland & 1952 & \\
\hline
\end{tabular}




\begin{tabular}{|c|c|c|}
\hline $\begin{array}{l}\text { Biblioteca Israelita Brasileira } \\
\text { Scholem Aleichem (BIBSA) } \\
\text { Associação Scholem Aleichem } \\
\text { de Cultura e Recreação (ASA) }\end{array}$ & $\begin{array}{l}1915 \\
1964\end{array}$ & $\begin{array}{l}\text { Praça Once-Botafogo, } \\
\text { Río de Janeiro }\end{array}$ \\
\hline $\begin{array}{l}\text { Biblioteca David Frischman } \\
\text { Associação David Frischman (ADAF) }\end{array}$ & $\begin{array}{l}1922 \\
1960\end{array}$ & Icaraí, Niterói, Río de Janeiro \\
\hline $\begin{array}{l}\text { Centro Operario Brasileiro Morris } \\
\text { Winchevsky }\end{array}$ & 1928 & Río de Janeiro \\
\hline Club de Cabiras & 1950 & Río de Janeiro \\
\hline $\begin{array}{l}\text { Liga Cultural Israelita } \\
\text { Club de Cultura de Porto Alegre }\end{array}$ & $\begin{array}{l}1932 \\
1950\end{array}$ & $\begin{array}{l}\text { Porto Alegre, } \\
\text { Rio Grande do Sul }\end{array}$ \\
\hline $\begin{array}{l}\text { Cozinha Popular da Praça Onze } \\
\text { (Árbeter Kich) }\end{array}$ & 1937 & Praça Onze, Río de Janeiro \\
\hline $\begin{array}{l}\text { Escola Israelita Brasileira } \\
\text { Eliezer Steinbarg }\end{array}$ & 1953 & Laranjeiras, Río de Janeiro \\
\hline Escuela I.L.Peretz & ca.1950 & Madureira, Río de Janeiro \\
\hline $\begin{array}{l}\text { Instituto Cultural Israelita Brasilero (ICIB) } \\
\text { Casa do Povo (Folks Hoiz) } \\
\text { con Escola Scholem Aleijem, } \\
\text { Kinder-club I.L. Peretz y Teatro de } \\
\text { Arte Israelita Brasileño (TAIB) }\end{array}$ & $\begin{array}{l}1920 \\
1953 \\
1960\end{array}$ & Bom Retiro, São Paulo \\
\hline $\begin{array}{l}\text { Sociedade Cultural Israelita Brasileira } \\
\text { (SOCIB) }\end{array}$ & 1953 & Paraná, Estado de Paraná \\
\hline Sociedad Israelita de Bahía & 1947 & Salvador de Bahía \\
\hline $\begin{array}{l}\text { Unión Israelita de Belo Horizonte } \\
\text { Escuela Israelita Peretz }\end{array}$ & 1922 & $\begin{array}{l}\text { Belo Horizonte } \\
\text { Minas Gerais }\end{array}$ \\
\hline \multicolumn{3}{|c|}{ CHILE } \\
\hline $\begin{array}{l}\text { Sociedad Progresista Israelita } \\
\text { Centro Cultural Scholem Aleijem }\end{array}$ & $\begin{array}{l}1938 \\
1951\end{array}$ & Santiago de Chile \\
\hline
\end{tabular}

